\title{
Route Expansion in the European Air Transport Market
}

\author{
Joan Calzada* \& Xavier Fageda**
}

\begin{abstract}
This paper examines the factors accounting for the significant increase in new routes in the European air transport market in the period 2002-2013. We consider a dataset for the 259 airports with more 250,000 passengers per year. Our data show that the creation of routes smoothly decreased after the economic crisis of 2008 and low-cost airlines are responsible for most of the increase in the number of routes between the airports examined. Our multivariate analysis reveals that the creation of new services has been more important in tourist routes and that new routes are concentrated at hub or secondary airports dominated by one airline. Furthermore, new routes are less likely in competitive environments. Finally, we find different opening patterns by low cost and network airlines and low-cost airlines provide services with lower frequencies and bigger planes than network carriers.
\end{abstract}

Keywords: New airline routes; low-cost airlines; network airlines; region connectivity.

JEL Codes: L13; L93; R40

Acknowledgments: We are grateful to two anonymous referees for their detailed comments and suggestions. We are also thankful for the comments received during the Workshop on Air Transport at University of Barcelona. We acknowledge financial support from Ministerio de Economía y Competitividad (ECO2015-69193-R).

* University of Barcelona. Department of Economics. Av. Diagonal 696, 08034 Barcelona, Spain. Tel.: +34934034374; e-mail: calzada@ub.edu.

** University of Barcelona, Department of Applied Economics, GIM-IREA. Av. Diagonal 690, 08034

Barcelona, Spain. Tel.: +34934039721; e-mail: xfageda@ub.edu. 


\section{Route Expansion in the European Air Transport Market}

\section{Introduction}

The European air transport market has undergone a significant expansion in recent years (Burghouwt and de Wit, 2015; Dobruszkes, 2014). In this regard, the creation of new routes has enhanced the connectivity of European airports, contributing to the economic and social development of its cities and regions (Button and Taylor, 2000; Blonigen and Cristea, 2015; Albalate and Fageda, 2016; Zeigler et al., 2017). The associated literature reports a causal linkage between the increase in air passenger transport and regional development in Europe, with positive consequences for job creation and tourism, among others. ${ }^{1}$ However, many regions have yet to benefit from this process, thus weakening their integration in the European Single Market and undermining the opportunities of their citizens and firms alike. The situation raises two questions: What route characteristics attract the interest of airlines? What measures can national and regional governments implement to improve the connectivity of their airports? To shed some light on these questions, this paper analyzes the factors favoring the creation of new routes in the European market in the period 2002-2013.

The increase in the number of active routes in Europe might be attributed to various causes. First, following the full liberalization of air transport services in 1997, European airlines were allowed to operate routes connecting airports within the European Economic Area (EEA) and Switzerland. ${ }^{2}$ In the period that followed, the creation of new routes was favored by the social and economic integration of European countries, which transformed consumers' travel habits and firms' spatial patterns. The benefits of liberalization, in terms of competition, prices and passenger volumes, have been analyzed extensively in the literature, with various papers focusing on the entry and exit strategies of low-cost carriers (i.e. Piga and Filippi, 2002; Gil-Moltó and Piga, 2008; Goolsbee and Syverson, 2008). Yet, few papers have analyzed the specific characteristics of either regions or airports that acted as an incentive for the creation of new routes by carriers in a competitive environment. More specifically, there

\footnotetext{
${ }^{1}$ The causality of the relationship between air transport and economic development is controversial and has been tested in several papers. See, among others, Button et al. 1999; Percoco, 2010; Dobruszkes et al., 2011; Mukkala and Tervo 2013; Bottasso et al., 2013; Baker et al., 2015; Van de Vijver et al., 2016).

2 The EEA currently includes the Member States of the European Union, as well as Iceland, Liechtenstein and Norway. The EEA-EU air market liberalization came into force on 1 July 1994 (1 April 1997 for cabotage), while EU-Switzerland air liberalization was introduced on 1 June 2002.
} 
is little evidence as to how airlines determine which routes to enter when configuring their hub-and-spoke (HS) and point-to-point (PP) systems.

A second plausible explanation for the creation of new routes is the introduction of regional jets that took place in the 1990s. Today, regional jet technology permits higher frequency services to be provided on longer thin routes than would be possible with turboprops. One hypothesis that has been tested in the literature is that turboprops and regional jets have contributed to the opening up of new routes previously considered uneconomical (Dresner et al., 2002; Brueckner and Pai, 2009; Fageda and Flores-Fillol, 2012). However, there is no clear evidence that the advantages of regional jets on mediumhaul routes have been exploited in either the US or the EU to create new air markets.

Finally, a third hypothesis to account for market expansion is that the competitive advantages of low-cost carriers have favored entry on thin routes (Barrett, 2004; Dobruszkes et al., 2011). These carriers have been able to reduce the costs of operating PP routes by implementing a business model based on the intensive use of aircraft and crews, lower labor costs, lower airport charges and a simpler management model, which involves using only one type of plane and a single fare class (Graham, 2009; Vera-Rebollo \& Ivars-Baidal, 2009).

A number of papers have examined the effects of low-cost airlines on prices and quality, but few studies have looked in detail at the characteristics of the new routes they have been created. One exception that we are aware of is Gil-Moltó and Piga (2008), who analyze the entries and exits of airlines on European routes departing from the ten main UK airports for the period 1997-2004. They find that the low-cost carriers were responsible for a large share of market entries, especially in countries recording the largest shares of passenger traffic and on routes not previously operated by network carriers. A related study is Dobruszkes et al. (2011), who analyze the determinants of the concentration of air services in the major European urban regions. They illustrate the importance of the metropolitan features of urban regions, including GDP, the level of economic decision-making power, tourist functions, and the distance between air markets in accounting for the variation in the presence of air services in a region.

Finally, although our paper reports an empirical examination of the main factors underpinning the creation of new routes in the European airline market, it is similar to the line of literature that analyzes the determinants of air services on existing routes (Cattan, 1995). More recently, several papers have employed gravity models to estimate air passenger 
volumes between city-pairs (Jorge-Calderón, 1997; Grosche et al., 2007; Zhang et al., 2016). These studies consider geo-economic variables that describe the regions that are connected and the characteristics of the routes. They also consider service-related characteristics that are controlled by the airlines, including prices and frequencies. At the same time, a growing number of studies have considered how passenger demand growth and self-connectivity affect airport connectivity and route development (Suau-Sánchez et al., 2016).

To study factors that might account for the opening of new routes in the European market, we use a rich data set for all potential routes between the 259 airports with more than 250,000 passengers in $2013 .^{3}$ The data set contains information about the characteristics of the routes, the airports, the regions, and the airlines operating the service in the period 20022013, that is, it commences eight years after market liberalization. The main novelty provided by our econometric analysis is that we identify the factors that explain both the opening of new routes and the capacity (flight frequency and aircraft size) used by the airlines to operate them. We also examine the factors determining route closures and the patterns of expansion followed by both network and low-cost airlines.

The rest of the paper is organized as follows. Section 2 describes the dataset used in this study. Section 3 presents the main trends in the European market and explains the estimation strategy for the multivariate analysis. Section 4 analyzes the factors affecting the opening of new routes and discusses their implications. Section 5 describes and accounts for the patterns of expansion taken by network and low-cost airlines. Finally, Section 6 concludes.

\section{Data}

We draw on a dataset for the EEA and Switzerland covering the period 2002-2013. Annual supply data (flight frequencies and plane size) at the airline-route level were obtained from RDC aviation (capstats statistics).

In building our sample we consider all potential non-stop routes between Europe's 259 largest airports (more than 250,000 passengers in 2013). Figure 1 shows that the airports considered in our sample operate about $90 \%$ of the flights in the European airline market $($ EEA + Switzerland), and are responsible for a similar percentage of new routes. Since our

\footnotetext{
${ }^{3}$ Our study does not consider airports with fewer than 250,000 passengers per year, where much of the traffic is likely to be connections to just one (or very few) destination. Other studies have used alternative thresholds to classify small airports: Redondi et al. (2013) consider airports below 2 million passengers a year; Suau-Sanchez et al. (2016b) below 2.5 million passengers; and Zeigler et al. (2017) below 4 million passengers.
} 
objective is to analyze the creation of new routes between these airports, we exclude from our analysis all routes that were active in 2002 and 2003. We also exclude all potential routes with a flight distance under 200 kilometers, since they are generally uneconomical for airlines and could distort our analysis.

\section{Insert Figure 1 about here}

We define routes as air services between two distinct airports, which means that one citypair market (e.g., London-Barcelona) may include several routes. In total, our sample considers a universe of 66,822 bidirectional routes. However, here we specifically opt to focus on non-directional routes and so our potential sample comprises 33,411 routes. Clearly, as frequencies are exactly (or almost) identical in both directions, treating airline services on a given route as directional would add no additional information and could actually yield incorrect standard errors. After excluding routes with a flight distance of under 200 kilometers and routes with air services in 2002 and 2003, the resulting sample of potential new routes for 2002-2013 contains 361,936 observations (overall, we consider 30,171 airport pairs for 12 years, but data for some variables in some periods are missing). In the empirical analysis, we consider that a route has been created when at least one airline operates one of the routes that was not served in the previous year.

The final sample contains 349,800 observations because some of the new routes might subsequently be shut down after creation. New routes are excluded from our dataset after the year of their creation, but included again after discontinuation. For example, direct flights on the Aberdeen-Glasgow route were introduced in 2006 but since that date have always been operative. Hence, we exclude this route from the analysis of openings for the period 20072013. Alternatively, the Dortmund-Malaga route was opened in 2006, closed in 2009, but reopened with a direct flight in 2013. To capture this set of events, we exclude the observations for this route from our sample for the period 2007-2008. This approach allows us to examine the relevance of a route's characteristics in the year in which the route was actually created. Indeed, the air market is highly dynamic and airlines open and close routes frequently. To illustrate this, Figure 2 shows the annual number of openings and closures in the period examined. 
Our dataset distinguishes between hub, secondary, tourist and other types of airport. Table A1 in the appendix shows the classification of airports used in our sample. By definition, hub airports are those at which a network airline exploits transfer traffic through coordinated banks of arrivals and departures. Our dataset includes 23 hub airports dominated by a network airline in the period 2002-2013. We also consider 18 secondary airports that are located no further than 100 kilometers from their respective city centers and which are usually dominated by one or more low-cost airlines. The dataset also includes 40 airports that can be considered as serving tourist destinations, including islands in the south of Europe, and tourist cities such as Alicante, Malaga, Nice, Faro and Innsbruck. Note that cities like London, Paris, Rome, Barcelona and Amsterdam are leading tourist destinations but their airport traffic is a mix of passengers travelling both for business and leisure purposes. Thus, we consider as tourist destinations those airports where most of the traffic is for tourism. The remaining airports in the sample are located close to medium-sized cities and are not dominated by one airline. Finally, there is a group of cities served by more than one airport. We define multiairport cities as those that have more than one airport within a $50-\mathrm{km}$ radius of the city.

Routes can be operated by network, low-cost, or other types of airline. Table A2 in the appendix presents the classification of the airlines considered in our analysis. Our dataset includes information from 22 network airlines that were former flag carriers for their respective corresponding countries and which operate an HS system. In general, when we refer to network airlines we include their regional subsidiaries. We also consider 40 low-cost airlines that operate a PP system. Finally, the dataset includes 81 additional airlines. These are mainly regional carriers (but not subsidiaries of network airlines), charter airlines that operate scheduled flights, and airlines that combine the characteristics of network and low-cost airlines. Interestingly, some of the airlines considered have modified their business strategy in recent years resulting in a change in their classification. For example, Air Berlin can be considered a low-cost airline in the period analyzed here, but it has recently become a hybrid airline. Despite this, the main results of our analysis are unaffected by these sorting decisions.

In the empirical analysis, we also consider the mean population and per capita GDP at the route endpoints. Information for these variables refers to the NUTS 3 regions (one of the statistical units used by Eurostat) and was provided by Cambridge Econometrics (European Regional Database publication). Note that airports are seldom located in the center of the NUTS 3 regions and so their catchment areas usually cover multiple statistical regions. The 
purpose of using these variables, however, is not to capture the size of the catchment areas where the airports are located but rather the size of the closest urban center. Nevertheless, this potential limitation associated with using the NUTS-3 classification should be borne in mind when interpreting our results. Finally, we also use great-circle distance data that were obtained from the website webflyer.com.

Table B1 in Appendix B shows the descriptive statistics of the variables used in the empirical analysis conducted herein and Table B2 shows the correlation matrix of the explanatory variables considered. Clearly, the correlation between the variables is not high which rules out the possibility of a problem of multicollinearity.

\section{Basic trends presented by new routes}

Before analyzing the characteristics of the new routes, we describe the evolution taken by the European airline market in the period 2003-2013. Figures 2 and 3 present the opening and closure of routes by all airlines. Figure 2 shows that in this period 2,306 new routes were created between the 259 airports considered. Interestingly, the creation of routes decreased smoothly after the economic crisis of 2008 , at the same time as the number of closures increased. Figure 3 shows that the increase in the number of routes was driven primarily by low-cost airlines, which opened 1,717 routes. Network airlines created 369 new routes, and on 55 of these they competed with a low-cost airline. This suggests that the two types of airline have developed different expansion strategies and that they usually operate new routes as monopolies.

\section{Insert Figure 2 about here Insert Figure 3 about here}

Recent papers have suggested a possible slowdown in the expansion of low-cost airlines, since new routes involve larger distances and lower volumes of traffic (de Wit and Zuidberg, 2012; Burghouwt and de Wit, 2015). This might account for the change in strategy of some airlines, including Ryanair, which in recent years have adopted a hybrid business model, entering the main airports so as to compete with traditional airlines (Fageda et al., 2015; Daft and Albers, 2015; Dobruszkes et al., 2017). 
To complete our analysis, Figures B1 and B2 in Appendix B show information about new routes in the European market that are not considered in the regression analysis conducted in Section 4. Figure B1 shows that the growth in the number of short-haul routes has been modest and that after 2008 they increased at a slower rate. Interestingly, many of these routes are operated by regional airlines that are not subsidiaries of network operators. In contrast, Figure B2 shows that the creation of new routes in the small airports not covered in our analysis increased throughout the period and that most of these routes were created by lowcost airlines.

Finally, to explore in greater detail the opening patterns in the European market we consider two important characteristics of the air services provided by the airlines, namely, the frequency of service and plane size. Figure B3 in Appendix B shows that the mean frequencies operated by airlines on new routes increased from 195 to 239 (22.5\%) between 2002 and 2013, and that plane size, measured by the number of seats, increased from 117 to $165(41.0 \%)$. The mean daily frequency of new routes is relatively low (0.42 daily flights), falling slightly in the last years of the period, which confirms the belief that new routes tend to be thinner. The increase in plane size suggests that technological innovation, and, in particular, the use of regional jets, is not the main driver of the creation of new routes.

The main conclusion we draw from this analysis is that the expansion of the European market in this period was determined primarily by the entry of low-cost airlines. Meanwhile, network airlines abandoned some routes and entered others deemed more profitable or which were a better fit in their overall business strategy; however, their expansion was only modest. The increase in the number of routes operated by network and low-cost airlines increased competition, but most of these new routes are served in a monopoly regime. From the perspective of the airports, the new routes favored above all tourist destinations, but hub and secondary airports also benefited. The section that follows examines these trends in greater detail.

\section{Multivariate analysis}

The objective of our empirical analysis is twofold. First, we examine the characteristics of the new routes created in the European market and the strategy used by airlines to operate them: 
that is the frequencies and sizes of the planes offered on the new routes. And second, we analyze the different patterns followed by low-cost and network airlines.

\subsection{Route openings in the period 2003-2013}

This section employs a two-step Heckman model for the joint identification of the factors that influenced the creation of new routes in the European market, and the frequencies and plane sizes used by the airlines to operate them. The estimation of flight frequencies and plane sizes may be affected by a sample selection bias, which we address by applying the Heckman correction. The first stage of the model considers a probit regression in which the dependent variable is Opening. This is a dummy variable that takes a value of 1 when at least one airline operates the route and 0 otherwise. ${ }^{4}$ Recall that new routes are excluded from our dataset after the year of their creation but are included again after being discontinued. The results of this regression are then used to predict the probability of air services on the route. The secondstage equation corrects for self-selection by incorporating a transformation of these predicted individual probabilities as an additional explanatory variable in the estimation of the route characteristics, that is, the Frequency with which the routes are operated and the Plane Size.

Taking this into account, we estimate the following two equations using data on route $k$ in year $t$ :

Opening $_{k t}=\alpha_{1}+\beta_{1} \log (\text { Population })_{k t}+\beta_{2} G D P_{k t}+\beta_{3}$ Distance $_{k}+\beta_{4}$ Distance $_{k}{ }_{k}+\beta_{5} D^{\text {Tourist }}{ }_{k}+\beta_{6} D^{\text {Domestic }}{ }_{k}$ $+\beta_{7} D_{k t}^{H S T}+\beta_{8} D^{\text {Multicity }}{ }_{k}+\beta_{9} D_{k}^{H u b}{ }_{k}+\beta_{10} D_{k}^{\text {Secondary }}+\beta^{\prime}$ Year $_{t}+\varepsilon_{k t}$;

$Y_{k t}=\alpha_{2}+\delta_{1}$ Network_airline $_{k t}+\delta_{2}$ Low-Cost_airline $_{k t}+\delta_{3}$ Log $\left(\right.$ Population $_{k t}+\delta_{4} G D P_{k t}+\delta_{5}$ Distance $_{k}+$ $\delta_{6}$ Distanc $^{2}{ }_{k}+\delta_{7} D^{\text {Tourist }}{ }_{k}+\delta_{8} D^{\text {Domestic }}{ }_{k}+\delta_{9} D^{\text {HST }}{ }_{k t}+\delta_{10} D^{\text {Multicity }}{ }_{k}+\beta{ }^{\prime}$ Year $_{t}+\varepsilon ;$

where the dependent variable $Y_{k t}$ is either the Frequency or the Plane Size. As explanatory variables, we include the $\log$ of the mean population (Log Population) ${ }^{5}$ and mean GDP per capita $(G D P)$ in the route's regions of origin and destination. The mean is weighted by the population of each of the route's endpoints. Routes that link the wealthier and more highly

\footnotetext{
${ }^{4}$ We consider an airline to operate a route when it offers more than one non-stop flight per week in each year. Since we use annual data we do not consider the seasonality of traffic.

${ }^{5}$ This variable is included in the model in $\operatorname{logs}$ to account for a possible non-linear effect of the population.
} 
populated cities should present greater demand, which should increase the probability of being served. Likewise, airlines should offer higher frequencies and employ larger planes on these routes. GDP per capita may also be considered a proxy of the proportion of travelers presenting a high willingness to pay at the route's two endpoints. Specifically, it should reflect the presence of more business passengers, who are more sensitive to time and less sensitive to price than leisure passengers. We expect network airlines to be more interested in entering these routes than other airlines since the former offer a high quality service, at least in terms of flight frequency. However, wealthier regions may also attract other types of visitor due to the externalities generated or because of their attractiveness to tourists.

Our model, as presented up to this point, resembles the gravity models frequently used in the literature to examine the demand for air transport services. In the modeling process, socioeconomic variables are considered exogenous as they refer to the region or urban area, while the route just considers a link with another urban area or region. As such, an endogeneity bias could arise if in so doing we were considering the activity of the whole airport as opposed to that of single routes.

The dummy variable $D^{\text {Tourist }}$ is included to account for the demand generated by tourist destinations. This variable takes a value of 1 for those routes where at least one of the endpoints is a tourist destination. Controlling for population and GDP per capita, demand should be higher and the service more profitable on routes that connect to a tourist destination. Moreover, we expect airlines to use larger planes and to offer lower frequencies on these routes, since leisure travelers are more willing to adjust their flight schedules to obtain lower prices.

Another explanatory variable of relevance to our analysis is the route distance (Distance). In general, demand is negatively related to route distance, although short-haul routes may be affected by strong competition from road and rail. To account for a possible non-linear effect of Distance, we include in the model a quadratic function of this variable. Furthermore, we expect plane size to increase and frequencies to decrease with route distance, since the cost effectiveness of mainline jets with respect to that of regional jets and turboprops increases with distance.

The dummy variable $D^{\text {Domestic }}$ indicates if the new route is domestic or international. Airlines might be interested in operating domestic routes because of the strong economic, social or political relations between the populations living at the route's two endpoints. However, competition with surface transport (essentially, road and rail) may be high on these 
routes, forcing airlines to offer high capacities (Dobruszkes et al., 2014). Taking this into account, we also include the dummy variable $D^{H S T}$, which takes a value of 1 for routes in which airline competes with high speed trains, and zero otherwise. Indeed, airlines may have little interest in opening routes that compete with high speed trains, but once they create them they may need to offer more flights so as to increase competitiveness.

We also consider the characteristics of the airports connected by the routes. The dummy variable $D^{H u b}$ reflects the fact that a route includes the hub airport of a network airline, and the dummy variable $D^{\text {Secondary }}$ indicating that a route includes a secondary airport dominated by a low-cost airline as its endpoint.

To reflect the presence of several airports offering transportation services in a city, we include a dummy variable for multi-airport cities, $D^{\text {Multicity }}$. This allows us to identify any differences between routes that connect cities with just one airport and routes where at least one of the endpoints is a multi-airport city. Here, it should be borne in mind that the dummy $D^{\text {Secondary }}$ refers to routes on which at least one of the airports is secondary, and $D^{\text {Multicity }}$ to routes on which at least one of the endpoints is a multi-airport city. Thus, for example, on the London-Heathrow to Barcelona route we have $D^{\text {secondary }}=0$ and $D^{\text {multicity }}=1$.

The variables Network_airline and Low Cost_airline are used to examine how the business models of network and low-cost airlines, respectively, affect Frequency and Plane Size. Finally, all the regressions include unreported year effects.

\subsection{Results}

The Heckman estimation allows us to consider the factors determining the creation of new routes and those that influence their Frequency and Plane Size. We also undertake a bootstrap estimation of the standard errors so as to take into account the correlation between the different observations for each route. ${ }^{6}$

Table 1 presents the results of our analysis. The first two columns refer to the Frequency estimation and the last two to the Plane Size estimation. We start by examining columns I and III, that is, the estimation of Openings in equation (1). The results of the two regressions are very similar, with the variables Population and GDP per capita both being positive and statistically significant, This confirms that new services are more likely to be created on

\footnotetext{
${ }^{6}$ We cannot apply a panel-data model in our econometric estimation. A fixed effects model cannot be used because it does not capture time-invariant variables (most of our explanatory variables are time-invariant). For the same reason, a dynamic panel model is not applicable. Furthermore, a random effects model may be inconsistent as the correlation between the random effects and the explanatory variables may be high.
} 
routes linking more highly populated and wealthier regions. We also find that the creation of air services is more likely on shorter routes.

In the period analyzed, airlines were less likely to create routes that could be exposed to some type of competition, such as domestic routes, routes that compete with high speed trains, or routes in multi-airport cities. In contrast, the creation of air services was more likely on routes with a tourist destination as an endpoint, or with a hub or secondary airport.

\section{Insert Table 1 about here}

Columns II and IV refer to the estimation of equation (2), which analyzes the frequencies and sizes of airplanes on new routes. A key finding to emerge from this estimation is that lowcost airlines use larger planes and offer lower frequencies than network airlines. There are two possible explanations for this: First, from a demand perspective, low-cost airlines may be operating on routes that are less dense; and, second, low-cost airlines use large planes and operate low flight frequencies to keep costs low.

Our analysis also shows that airlines provide higher frequencies on routes that link wealthier endpoints. In contrast, they use smaller planes on routes that link more highly populated endpoints. From these results it can be inferred that regional carriers using smaller planes at higher frequencies tend to operate on denser routes (that is, routes with endpoints having more population and higher GDP per capita). Furthermore, as expected, airlines use larger planes and provide lower frequencies on longer routes.

Our results in columns I and III show that airlines are less likely to create new routes in competitive environments, possibly because they have to offer higher frequencies and/or use larger planes. This intuition is confirmed by our results in columns II and IV, where we find that airlines operate higher capacities on routes that compete with high speed trains and on those that connect with multi-airport cities. Finally, flight frequencies are lower on new routes with tourist destinations as an endpoint, possibly due to a greater proportion of leisure passengers.

In Section 3 we saw that the dynamics of the air transport market changed after 2008, with a slowdown in the creation of new routes and an increase in the number of routes being shut down. There are two main factors that account for this. First, the eastward expansion of the European Union in 2004 favored an increase in connectivity between the airports of Eastern 
and Western Europe. ${ }^{7}$ Second, the economic crisis unleashed in 2008 impacted the profitability of thinner routes. To account for this, Table B3 in Appendix B shows an additional set of regressions in which we split the sample in two periods: 2002-2008 and 2008-2013. We find that the factors accounting for the opening up of new routes are similar in the two sub-periods, but some of these results need to be examined in greater detail. In the period 2008-2013, the frequency differential between network and low-cost airlines increased markedly, while the plane size differential remained similar in the two sub-periods. As a result, network airlines operated their new routes at higher capacities, reflecting their interest in denser routes.

We also find a higher probability of openings on domestic routes in the period 2002-2008 and a higher probability of openings on international routes in the period 2008-2013. The growing economic, political and social integration between the European countries and the enlargement of the EU appears to have increased the profitability of certain international routes. In addition, by the end of the period most of the dense domestic routes were already served by direct flights. Finally, openings on routes with secondary airports as endpoints is increasing over time. The continuous expansion of low-cost airlines, most notably Ryanair, that operate from secondary airports may account for this result.

\subsection{Route closures in the period 2003-2013}

To analyze the airlines' incentives to close existing routes, we consider a new sample made up solely of active routes and examine the factors determining their discontinuity. Table 2 shows the results of the estimation using a logit model. Column 1 considers the whole period, while columns II and III present our findings for the intervals 2002-2008 and 2008-2013, respectively. Interestingly, we find that domestic routes and routes with a hub airport as an endpoint are more likely to be closed. This suggests that some of the routes traditionally operated by network carriers may not be profitable on a permanent basis. In contrast, tourist routes and routes with a secondary airport as an endpoint, which are frequently operated by low-cost airlines, are less likely to be closed. Finally, we also find

\footnotetext{
${ }^{7}$ Ten new countries joined the EU in 2004: the Czech Republic, Estonia, Cyprus, Latvia, Lithuania, Hungary, Malta, Poland, Slovakia and Slovenia. In 2007, Bulgaria and Romania also joined the EU. See https://ec.europa.eu/neighbourhood-enlargement/policy/from-6-to-28-members_en
} 
that wealthier routes were more likely to be closed in the 2002-2008 period, although they were less likely to be closed after 2008 .

\section{Insert Table 2 about here}

\section{Low-cost vs. network airlines}

This section studies the possible presence of different opening patterns among low-cost and network airlines, respectively. We employ the same methodology as in the previous section, but here our dependent variable in the first stage of the Heckman model reflects whether the route was created by a low-cost or by a network airline. In this set of regressions we do not include the secondary airport dummy variable given that, by definition, these airports are dominated (if not monopolized) by low-cost airlines. In contrast, we do include the hub airport dummy because these airports offer their services to different types of airlines, although there is a tendency for them to be dominated by network airlines.

Table 3 presents the results of this analysis. The first four columns show the estimations for low-cost airlines and the last four show the estimations for network airlines. We start by reporting the results in columns I, III, V and VII, which refer to the estimation of openings by both low-cost and network airlines. Both airline types opened routes connecting wealthy and highly populated regions, but the marginal effect of GDP per capita is higher for network airlines. This suggests that the latter are more interested in routes in which travelers present a high willingness to pay.

\section{Insert Table 3 about here}

Low-cost airlines are more likely to open long and international routes, while network airlines are more likely to open shorter routes. Note that the squared distance variable is now statistically significant and presents the opposite sign to that of the distance variable. Hence, the non-linear effects of distance are more clearly identified than they are in the regressions reported in Table 1. 
Both types of airline are more likely to open routes with a tourist destination or a hub as an endpoint. However, the marginal effect of the hub variable is much greater for network airlines, which illustrates their interest in increasing their presence in the airports that they already dominate. Furthermore, both network and low-cost airlines are less likely to open routes subject to intense competition. Indeed, the dummy variables for high speed train and multi-airport cities are negative and statistically significant in both cases.

Columns II and VI show the results when the dependent variable is flight frequencies, while columns IV and VIII report the estimates for plane size. Each low-cost airline usually operates a single plane model (perhaps with different seat configurations), but there may be differences between low-cost airlines in terms of the type of plane they fly. Additionally, network airlines may use relatively large planes when operating their main brand and smaller planes when operating their regional subsidiaries.

Our results show substantial differences in the capacity choices made by low-cost and network airlines, although both types of airline use larger planes with lower flight frequencies on longer and on tourist routes. Network airlines offer higher frequencies on routes with wealthier endpoints, indicative of the fact that an essential element of their business model is to provide high-frequency services to wealthier destinations.

Low-cost airlines also offer higher capacities on denser routes (routes with more highly populated and wealthier endpoints), but here this is achieved by using larger planes. Moreover, their flight frequencies do not depend on the economic and demographic characteristics of the endpoints of the routes.

Inter-modal competition appears to affect network airlines most. Thus, these airlines use smaller planes at lower frequencies on new domestic routes, while offering lower frequencies on new routes that compete with high speed trains, a situation that may be partially offset by the use of larger planes. In the case of low-cost airlines, we find a modest statistical impact of high speed trains on their capacity choices, but they offer higher frequencies and smaller planes on their new domestic routes. ${ }^{8}$

Finally, both network and low-cost airlines are required to provide higher frequencies on new routes that connect endpoints with multi-airport cities. In the case of low-cost airlines this is offset by the use of smaller planes.

\footnotetext{
${ }^{8}$ These results are consistent with previous findings in the literature. For example, Dobruszkes et al. (2014) report that low-cost airlines do not find it attractive to compete with high speed trains. Similarly, Givoni and Rietveld (2009) find that network airlines operate small planes at high frequencies to attract business passengers.
} 


\section{Conclusions}

Several empirical studies have examined the impact of air transport on economic development at the regional level. In general, they conclude that good air transport services and access to other markets provide incentives to companies to locate in a region, stimulate the expansion of existing firms, and attract investments and workers. In this context, improving air transport connectivity is essential for fostering economic development and convergence, especially in the case of remote and less developed regions.

Understanding the factors that determine the opening of new routes is critical for those agents operating in the airline market. First, airports compete to attract new airlines and new routes and, as such, they need to determine which routes are viable and more profitable for the airline operators. Second, airlines are anxious to know which routes are likely to generate more traffic and to be more profitable, and so they adjust their offer according to the presence of competitors, the growth in demand and the nature of national regulations. Finally, governments are interested in identifying the market characteristics that attract the interest of airlines, and they can use public service obligations, public aid, and other measures to increase the connectivity of their airports.

This paper has examined the factors that led to the creation of new routes in the European airline market in the period 2002-2013, some years after its liberalization. We find that new routes tended to concentrate on tourist destinations, on hub airports dominated by network carriers, and on secondary airports dominated by low-cost airlines. Furthermore, new routes are less likely to be opened in competitive environments.

We have also shown that network airlines increased only slightly the number of new routes on which they operate, and that they tended to consolidate their HS model by concentrating operations in large hub airports and by entering on short-haul routes and on routes with wealthier endpoints at higher frequencies. The strengthening of HS systems may have contributed to the expansion of low-cost airlines. In this regard, low-cost airlines opened PP services on long and international routes that traditionally had not been exploited by former flag carriers due to their network configuration.

Our analysis reveals that low-cost airlines extended the benefits of air connectivity to regions with relatively low rates of GDP per capita, increasing the geographical coverage of small or medium-sized airports. In spite of this, low-cost airlines tended to operate new routes with larger planes and at lower frequencies than those employed by network airlines. Further 
research needs to analyze the expansion strategies followed by the low-cost airlines, and how they have adapted their business models over time.

We recognize that the analysis presented herein is conditioned by a number of limitations. One aspect we have not considered, but which might have played a role in the creation of new routes, is the intervention of central and regional governments. First, governments facilitate airport development by providing legal authorization and by financing ground transport. Second, in recent years several regional governments have actively promoted air traffic by granting subsidies to the airlines, on the understanding that this increases connectivity, creating employment and fostering economic activity (Dobruszkes, 2006). And, finally, various European countries support the existence of thin routes by imposing public service obligations that regulate fares, flight frequencies, and market access (Calzada and Fageda, 2012 and 2014; Bottasso et al., 2017). The impact of such interventions on the European market is a critical subject for future studies in this field.

A second limitation of this study is that it has focused on airports with more than 250,000 passengers per year. To orientate public policy more effectively in this sector, it would be of considerable interest to identify the factors that affect the opening up of new routes at small airports, where airlines might adopt different strategies. In a recent paper, Zeigler et al. (2017) show that low-cost carriers entering small airports offer a better connectivity than that offered by network carriers, but that this has reduced the connectivity of network carriers. In this context, it would be insightful to examine the factors that favor the creation of new routes from airports of this type, and to determine how the entry of low-cost airlines in hub airports affects their connectivity. 


\section{References}

Albalate, D., \& Fageda, X. (2016). High-tech employment and transportation: Evidence from the European regions. Regional Studies, 50, 1564-1578.

Baker, D., Merkert, R. \& Kamruzzaman, M. (2015). Regional aviation and economic growth: cointegration and causality analysis in Australia, Journal of Transport Geography, 43, $140-150$.

Barrett, D. (2004). The sustainability of the Ryanair model. International Journal of Transport Management, 10, 33-39.

Blonigen, B.A., \& Cristea, A.D. (2015). Airports and urban growth, Evidence from a quasinatural policy experiment, Journal of Urban Economics, 86, 128-126.

Bottasso, A., Conti, M. \& Piga, C. (2013) Low-cost carriers and airports' performance: empirical evidence from a panel of UK airports, Industrial and Corporate Change, 22, $745-769$.

Bottasso, A., Bruno, M., Conti, M. \& Piga, C. (2017) Competition, vertical relationship and countervailing power in the UK airport industry, Journal of Regulatory Economics, 52, $37-62$.

Brueckner, J.K., \& Pai, V. (2009). Technological innovation in the airline industry: The impact of regional jets, International Journal of Industrial Organization, 27, 110-120.

Burghouwt, G., \& de Wit, J.G. (2015). In the wake of liberalisation: long-term developments in the EU air transport market, Transport Policy, 43, 104-113.

Button K. \& Taylor, S. (2000). International air transportation and economic development, Journal of Air Transport Management, 6, 209-222.

Calzada, J., \& Fageda, X. (2012). Discounts and Public Service Obligations in the Airline Industry: Lessons from Spain, Review of Industrial Organization, 40, 291-312.

Calzada, J., \& Fageda, X. (2014). Competition and Public Service Obligations in European Aviation Markets, Transportation Research-A, 70, 104-116.

Cattan. N. (1995). Attractivity and internationalization of major European cities: the example of air traffic, Urban Studies, 32, 303-312.

Daft, J. \& Albers, S. (2015). An empirical analysis of airline business model convergence. Journal of Air Transport Management, 46, 3-11.

de Wit, J. \& Zuidberg, J. (2012). The growth limits of the low cost carrier model, Journal Air Transport Management, 21, 17-23. 
de Wit, J. \& Zuidberg, J. (2016). Route churn: an analysis of low-cost carrier route continuity in Europe, Journal Transport Geography, 50, 57-67.

Dobruszkes, F. (2006). An analysis of European low-cost airlines and their networks, Journal of Transport Geography, 14, 249-264.

Dobruszkes, F., Lenner, M. \& Van Hamme, G. (2011). An analysis of the determinants of air traffic volume for European metropolitan areas, Journal of Transport Geography, 19, 755-762.

Dobruszkes F., Dehon C., Givoni M. (2014). Does European high-speed rail affect the current level of air services? An EU-wide analysis, Transportation Research Part A: Policy and Practice, 69, 461-475.

Dobruszkes F. (2014), Geographies of European air transport, in A. Goetz and L. Budd (Eds), Geographies of Air Transport, pp. 168-186. Farnham, UK: Ashgate

Dobruszkes, F., Givoni, M. \& Vowles, T. (2017). Hello major airports, goodbye regional airports? Recent changes in European and US low-cost airline airport choice, Journal of Air Transport Management, 59, 50-62.

Dresner, M., Windle, R., \& Zhou, M. (2002). Regional jet services: supply and demand. Journal of Air Transport Management, 8, 267-273.

Fageda, X., \& Flores-Fillol, R. (2012). Air services on thin routes: Regional versus low-cost airlines, Regional Science and Urban Economics, 42, 702-714.

Fageda, X., Suau-Sanchez, P. \& Mason, K. (2015). The evolving low-cost business model: network implications of fare bundling and connecting flights in Europe. Journal of Air Transport Management, 42, 289-296.

Florida, R., Mellander C. \& Holgersson, T. (2015). Up in the air: the role of airports for regional economic development, The Annals of Regional Science, 54, 197-214.

Gil-Moltó, M.J., \& Piga, C. (2008). Entry and Exit by European low-cost and traditional carriers, Tourism Economics, 14, 577-598.

Givoni, M. \& Rietveld, P. (2009). Airline's choice of aircraft size - Explanations and implications, Transportation Research Part A: Policy and Practice, 43, 500-510

Goolsbee, A., \& Syverson, C. (2008). How do incumbents respond to the threat of entry? Evidence from the major airlines, Quarterly Journal of Economics, 123, 1611-1633.

Graham, M. (2009). Different models in different spaces or liberalized optimizations? Competitive strategies among low-cost carriers. Journal of Air Transport Management, $16,127-136$. 
Grosche, T., Rothlauf, F. \& Heinzl, A. (2007). Gravity models for airline passenger volume estimation, Journal of Air Transport Management, 13, 175-183.

Heckman, J. (1979). Sample selection bias as a specification error. Econometrica, $47153-$ 161.

Jorge-Calderón, J.D., (1997). A demand model for scheduled airline services on international European routes, Journal of Air Transport Management, 3, 23-35.

Mukkala K. \& Tervo, H. (2013). Regional airports and regional growth in Europe: which way does the causality run?, Environment and Planning A, 45, 1508-1520.

Percoco, M. (2010). Airport activity and local development: evidence from Italy. Urban Studies, 47, 2427-2443.

Piga, C.A., \& Filippi, N. (2002). Booking and Flying with Low Cost airlines, International Journal of Tourism Research, 4, 237-249.

Suau-Sanchez, P., Voltes-Dorta, A. \& Rodríguez-Déniz, H. (2016), Measuring the potential for self-connectivity in global air transport markets: Implications for airports and airlines, Journal of Transport Geography, 57, 70-82.

Van de Vijver, E., Derudder, B. \& Witlox, F. (2016). Air Passenger Transport and Regional Development: Cause and Effect in Europe, Promet - Traffic \& Transportation, 28, 143154.

Vera Rebollo, J.F., \& Ivars Baidal, J.A (2009). Spread of Low-Cost Carriers: Tourism and Regional Policy Effects in Spain, Regional Studies, 43, 559-570.

Zhang, Y., Lin, F. \& Zhang, A. (2016). Gravity models in air transport research: A survey and an application, mimeo.

Zeigler, P., Pagliari, R., Suau-Sanchez, P., Malighetti, P. \& Redondi, R. (2017). Low-cost carrier entry at small European airports: Low-cost carrier effects on network connectivity and self-transfer potential, Journal of Transport Geography, 60, 68-79. 


\section{FIGURES}

Figure 1. Share of the sample airports in relation to the whole European market (EU + EFTA countries)

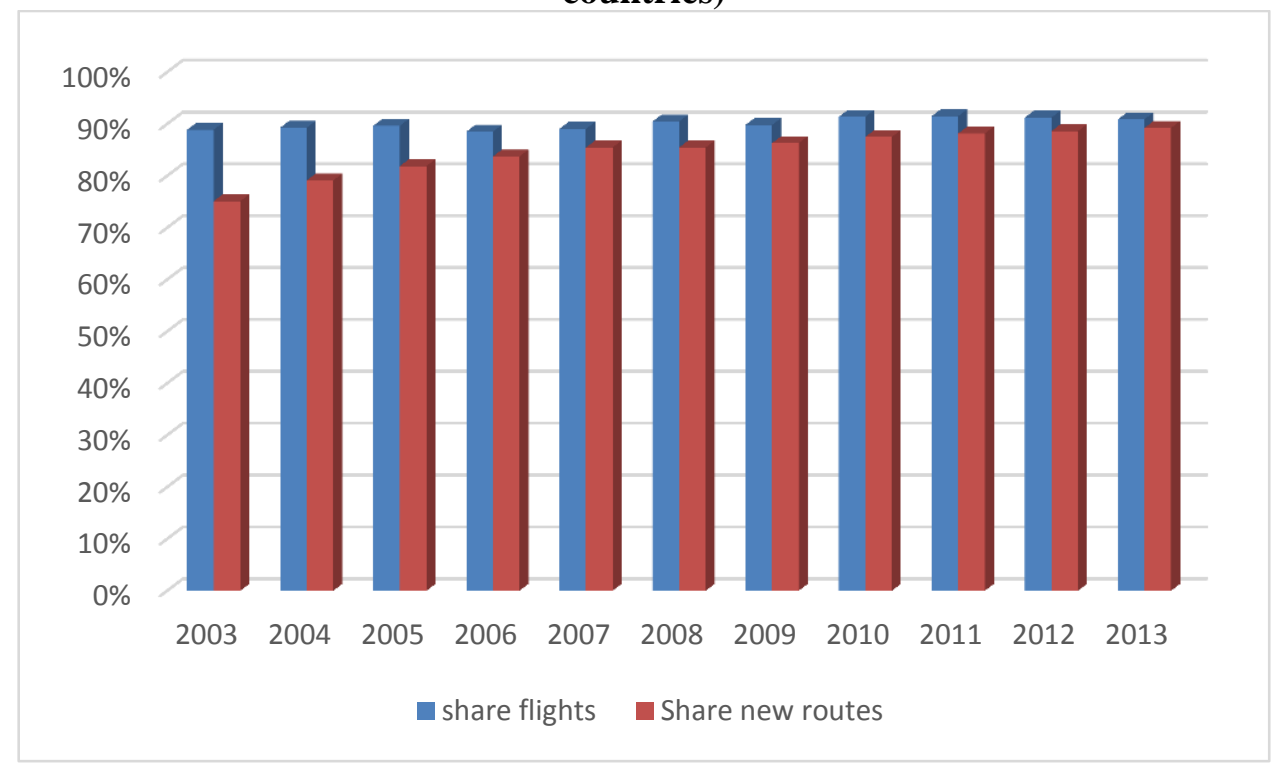

Figure 2. New Routes in the European Market

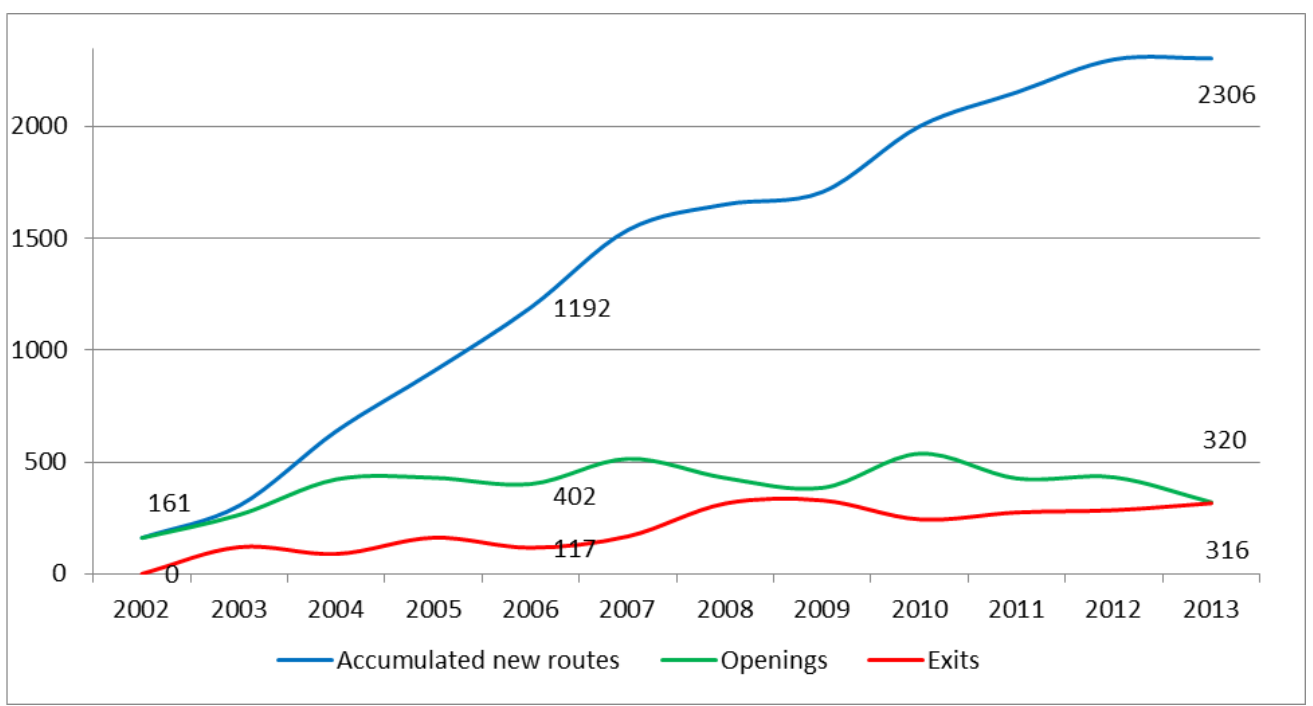

Note 1: Tourist airports have participated in 829 of the new routes (36\% of the total), secondary airports in 601 routes $(26 \%)$ and the hub airports in 599 routes $(26 \%)$.

Note 2: Net creation of new routes by country (we consider the nationality of the airports in each endpoints of the routes): Austria (35), Belgium (91), Bulgaria (31), Croatia (60), Cyprus (31), Czech Republic (34), Denmark (105), Estonia (17), Germany (358), Greece (170), Finland (23), France (323), Hungary (40), Iceland (14), Ireland (113), Italy (621), Lithuania (82), Luxembourg (8), Letonia (41), Malta (35), Netherlands (102, Norway (192), Poland (252), Portugal (95), Romania (73), Slovenia (4), Slovakia (21), Spain (704), Sweden (124), Switzerland (77), United Kingdom (742). 
Figure 3. New Routes in the European Market (by type of airline)

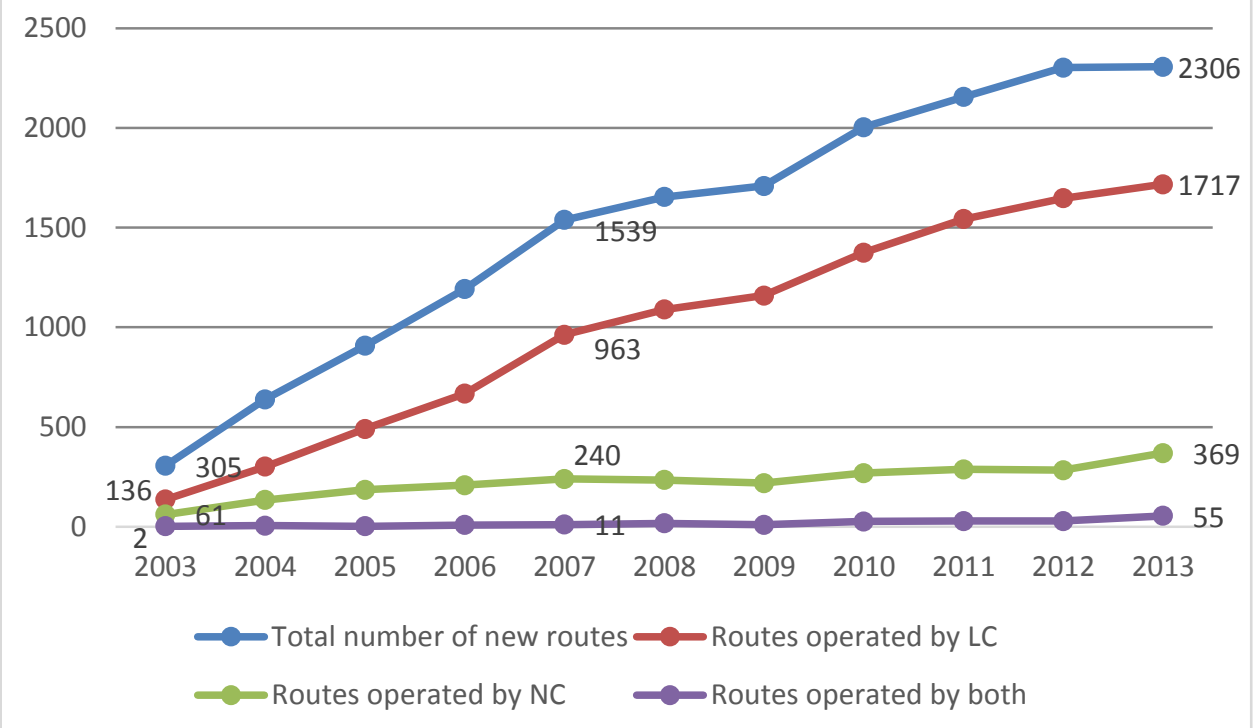

TABLES

Table 1. Route openings - All sample (Heckman two-step procedure)

\begin{tabular}{|c|c|c|c|c|}
\hline & $\begin{array}{c}\text { Dependent variable: } \\
\text { Opening }\end{array}$ & $\begin{array}{c}\text { Dependent variable: } \\
\text { Frequencies }\end{array}$ & $\begin{array}{l}\text { Dependent variable: } \\
\text { Opening }\end{array}$ & $\begin{array}{l}\text { Dependent variable: } \\
\text { Size of the plane }\end{array}$ \\
\hline & I & II & III & IV \\
\hline Network_airline & - & $0.27(0.03) * * *$ & - & $-0.13(0.01) * * *$ \\
\hline Low-Cost_airline & - & $0.09(0.02)^{* * *}$ & - & $0.46(0.01)^{* * *}$ \\
\hline Log(Population) & $0.17(0.007)^{* * *}$ & $-0.0007(0.01)$ & $0.17(0.007)^{* * *}$ & $-0.03(0.01)^{* * *}$ \\
\hline GDP per capita & $0.07(0.001)^{* * * *}$ & $0.001(0.0006)^{* *}$ & $0.07(0.01)^{* * *}$ & $-0.0007(0.0004)$ \\
\hline Distance & $-0.31(0.03) * * *$ & $-0.0005(0.00005) * * *$ & $-0.31(0.04) * * *$ & $0.0006(0.00002) * * *$ \\
\hline Distance $^{2}$ & $0.002(0.02)$ & $1.12 \mathrm{e}-07(1.29 \mathrm{e}-08)^{* * *}$ & $0.002(0.02)$ & $-1.00 \mathrm{e}-07(7.45 \mathrm{e}-09) * * *$ \\
\hline $\mathrm{D}^{\text {Tourist }}$ & $0.28(0.01)^{* * *}$ & $-0.24(0.04)^{* * * *}$ & $0.28(0.01)^{* * * *}$ & $0.02(0.01)$ \\
\hline $\mathrm{D}^{\text {Domestic }}$ & $-0.02(0.01)$ & $0.02(0.02)$ & $-0.02(0.01)$ & $-0.04(0.01)^{* * * *}$ \\
\hline $\mathrm{D}^{\text {hst }}$ & $-0.82(0.23) * * *$ & $0.39(0.36)$ & $-0.82(0.19)$ & $0.68(0.18)^{* * *}$ \\
\hline $\mathrm{D}^{\text {multicity }}$ & $-0.22(0.02)^{* * *}$ & $0.27(0.03)^{* * *}$ & $-0.22(0.02) * * *$ & $0.05(0.02)^{* *}$ \\
\hline $\mathrm{D}^{\text {hub }}$ & $0.31(0.01)^{* * * *}$ & - & $0.31(0.01)^{* * *}$ & - \\
\hline $\mathrm{D}^{\text {secondary }}$ & $0.29(0.01)^{* * *}$ & - & $0.29(0.01)^{* * *}$ & - \\
\hline Intercept & $-3.70(0.07) * * *$ & $6.44(0.31)^{* * *}$ & $-3.69(0.06) * * *$ & $4.77(0.17)^{* * *}$ \\
\hline$\lambda$ mills ratio & \multicolumn{2}{|c|}{$-0.40(0.07) * * *$} & \multicolumn{2}{|c|}{$-0.25(0.04)^{* * *}$} \\
\hline Test joint sign & \multicolumn{2}{|c|}{$2518.62 * * *$} & \multicolumn{2}{|c|}{$4944.07 * * *$} \\
\hline Number observations & \multirow{3}{*}{\multicolumn{2}{|c|}{$\begin{array}{c}349819 \\
345099 \\
4720\end{array}$}} & \multirow{3}{*}{\multicolumn{2}{|c|}{$\begin{array}{c}349808 \\
345099 \\
4709\end{array}$}} \\
\hline Censored observations & & & & \\
\hline $\begin{array}{l}\text { Uncensored } \\
\text { observations }\end{array}$ & & & & \\
\hline
\end{tabular}


Notes: Standard errors in parentheses (they are robust to heteroscedasticity and made with a bootstrap estimation). Statistical significance at $1 \%(* * *), 5 \%(* *), 10 \%(*)$. Unreported year fixed effects are included in the estimation. In the first-stage of the Heckman procedure, we report the marginal effects for dummies and the elasticities for continuous variables.

Table 2. Route closings - (logit)

\begin{tabular}{|c|c|c|c|}
\hline & \multicolumn{3}{|c|}{ Dependent variable: Closing } \\
\hline & All years (I) & Period 2002-2008 (II) & Period 2008-2013 (III) \\
\hline Log(Population) & $0.05(0.02)^{*}$ & $0.05(0.03)$ & $0.05(0.04)$ \\
\hline GDP per capita & $-0.0003(0.002)$ & $0.01(0.003)^{* * *}$ & $-0.02(0.004)^{* * *}$ \\
\hline Distance & $-0.05(0.007)^{* * *}$ & $-0.04(0.007)^{* * *}$ & $-0.05(0.01)^{* * *}$ \\
\hline Distance $^{2}$ & $0.02(0.003)$ & $0.02(0.002)^{* * *}$ & $0.02(0.007)^{* * *}$ \\
\hline $\mathrm{D}^{\text {Tourist }}$ & $-0.01(0.003)^{* * *}$ & $0.001(0.003)$ & $-0.03(0.005)^{* * *}$ \\
\hline $\mathrm{D}^{\text {Domestic }}$ & $0.02(0.003)^{* * *}$ & $0.02(0.003)^{* * *}$ & $0.03(0.005)^{* * *}$ \\
\hline $\mathrm{D}^{\text {hst }}$ & $-0.02(0.02)$ & $-0.02(0.01)$ & $-0.01(0.05)$ \\
\hline $\mathrm{D}^{\text {multicity }}$ & $0.002(0.005)$ & $0.002(0.003)$ & $0.004(0.009)$ \\
\hline $\mathrm{D}^{\text {hub }}$ & $0.008(0.003)^{* * *}$ & $0.008(0.003)^{* * *}$ & $0.009(0.005)^{* * *}$ \\
\hline $\mathrm{D}^{\text {secondary }}$ & $-0.02(0.002)^{* * *}$ & $-0.02(0.003)^{* * *}$ & $-0.03(0.005)^{* * *}$ \\
\hline Intercept & $-1.79(0.24)^{* * *}$ & $-2.38(0.21)^{* * *}$ & $-2.13(0.30)^{* * *}$ \\
\hline Test joint sign & $951.03 * * *$ & $1041.33 * * *$ & $158.91 * * *$ \\
Number observations & 37195 & 22454 & 18260 \\
\hline
\end{tabular}

Notes: Standard errors in parentheses (they are robust to heteroscedasticity and made with a bootstrap estimation). Statistical significance at $1 \%(* * *), 5 \%(* *), 10 \%(*)$. Unreported year fixed effects are included in the estimation. In the first-stage of the Heckman procedure, we report the marginal effects for dummies and the elasticities for continuous variables 
Table 3. Low cost and Network carriers (Heckman two-step procedure)

\begin{tabular}{|c|c|c|c|c|c|c|c|c|}
\hline & \multicolumn{4}{|c|}{ Low-cost carriers } & \multicolumn{4}{|c|}{ Network carriers } \\
\hline & $\begin{array}{l}\text { Dependent } \\
\text { variable: } \\
\text { Opening }\end{array}$ & $\begin{array}{l}\text { Dependent } \\
\text { variable: } \\
\text { Frequencies }\end{array}$ & $\begin{array}{c}\text { Dependent } \\
\text { variable: } \\
\text { Opening }\end{array}$ & $\begin{array}{c}\text { Dependent } \\
\text { variable: Size of } \\
\text { the plane }\end{array}$ & $\begin{array}{c}\text { Dependent } \\
\text { variable: } \\
\text { Opening }\end{array}$ & $\begin{array}{l}\text { Dependent } \\
\text { variable: } \\
\text { Frequencies }\end{array}$ & $\begin{array}{c}\text { Dependent } \\
\text { variable: } \\
\text { Opening }\end{array}$ & $\begin{array}{c}\text { Dependent } \\
\text { variable: Size } \\
\text { of the plane }\end{array}$ \\
\hline & I & II & III & IV & $\mathbf{V}$ & VI & VII & VIII \\
\hline Log(Population) & $0.21(0.008)^{* * * *}$ & $-0.05(0.09)$ & $0.21(0.009)^{* * *}$ & $0.10(0.04)^{* *}$ & $0.19(0.01)^{* * *}$ & $0.04(0.04)$ & $0.19(0.01)^{* * *}$ & $-0.007(0.02)$ \\
\hline GDP per capita & $0.04(0.01)^{* * *}$ & $0.001(0.0012)$ & $0.04(0.01)^{* * *}$ & $0.001(0.0005) * * *$ & $0.14(0.01)^{* * *}$ & $0.01(0.002)^{* * * *}$ & $0.14(0.02) * * *$ & $0.001(0.001)$ \\
\hline Distance & $0.13(0.05)^{* *}$ & $\begin{array}{c}-0.0006 \\
(0.00009)^{* * *}\end{array}$ & $0.13(0.04) * * *$ & $\begin{array}{c}0.0003 \\
(0.00005)^{* * *} \\
\end{array}$ & $-0.46(0.04)^{* * *}$ & $\begin{array}{c}-0.0009 \\
(0.0001)^{* * *} \\
\end{array}$ & $-0.48(0.05)^{* * *}$ & $\begin{array}{c}0.0008 \\
(0.00006)^{* * *} \\
\end{array}$ \\
\hline Distance $^{2}$ & $-0.23(0.03)^{* * *}$ & $\begin{array}{c}1.58 \mathrm{e}-07 \\
(4.06 \mathrm{e}-08)^{* * *}\end{array}$ & $-0.23(0.03) * * *$ & $\begin{array}{c}-9.19 \mathrm{e}-08 \\
(1.93 \mathrm{e}-08)^{* * *}\end{array}$ & $0.10(0.01)^{* * *}$ & $\begin{array}{c}1.53-\mathrm{e} 07 \\
(4.51 \mathrm{e}-08)^{* * *}\end{array}$ & $0.10(0.02) * * *$ & $\begin{array}{c}-1.26 \mathrm{e}-07 \\
(1.64 \mathrm{e}-08) * * *\end{array}$ \\
\hline $\mathrm{D}^{\text {Tourist }}$ & $0.23(0.01)^{* * *}$ & $-0.25(0.11)^{* *}$ & $0.23(0.01)^{* * *}$ & $0.13(0.04)^{* * *}$ & $0.19(0.02)^{* * *}$ & $-0.10(0.08)$ & $0.19(0.03)^{* * *}$ & $0.09(0.03) * * *$ \\
\hline $\mathrm{D}^{\text {Domestic }}$ & $-0.08(0.01)^{* * *}$ & $0.12(0.05) * * *$ & $-0.08(0.01)^{* * *}$ & $-0.09(0.01)^{* * *}$ & $0.04(0.03)$ & $-0.13(0.07)^{*}$ & $0.03(0.02)$ & $\begin{array}{c}-0.12 \\
(0.03) * * * \\
\end{array}$ \\
\hline $\mathrm{D}^{\mathrm{hst}}$ & $-0.92(0.13) * * *$ & $0.14(0.38)$ & $-0.92(0.15)^{* * *}$ & $-0.29(0.17)^{*}$ & $-0.69(0.13)^{* * *}$ & $-4.39(0.16)^{* * *}$ & $-0.72(0.14)^{* * *}$ & $1.03(0.09) * * *$ \\
\hline $\mathrm{D}^{\text {multicity }}$ & $-0.13(0.03) * * *$ & $0.38(0.06)^{* * *}$ & $-0.13(0.03) * * *$ & $-0.09(0.03)^{* *}$ & $-0.20(0.05)^{* * *}$ & $0.27(0.14)^{* *}$ & $-0.19(0.05)^{* * *}$ & $0.07(0.05)$ \\
\hline $\mathrm{D}^{\text {hub }}$ & $0.08(0.02)^{* * * *}$ & - & $0.08(0.02)^{* * *}$ & - & $0.59(0.02) * * *$ & - & $0.59(0.03)^{* * *}$ & - \\
\hline Intercept & $-4.60(0.08)^{* * *}$ & $8.55(2.39) * * *$ & $-4.60(0.08)^{* * *}$ & $2.01(1.06)^{*}$ & $-4.27(0.10)^{* * *}$ & $6.16(0.47)^{* * *}$ & $-4.26(0.10)^{* * *}$ & $3.99(0.29)^{* * *}$ \\
\hline$\lambda$ mills ratio & \multicolumn{2}{|c|}{$-0.95(0.50)^{*}$} & \multicolumn{2}{|c|}{$0.62(0.21)^{* * *}$} & \multicolumn{2}{|c|}{$-0.30(0.09)^{* * *}$} & \multicolumn{2}{|c|}{$-0.13(0.06)^{* *}$} \\
\hline Test joint sign & \multicolumn{2}{|c|}{$837.67 * * *$} & \multicolumn{2}{|c|}{$493.88 * * *$} & \multicolumn{2}{|c|}{$13021.60 * * *$} & \multicolumn{2}{|c|}{$4656.10 * * *$} \\
\hline $\begin{array}{c}\text { Number observations } \\
\text { Censored observations } \\
\text { Uncensored } \\
\text { observations }\end{array}$ & \multicolumn{2}{|c|}{$\begin{array}{c}354215 \\
350850 \\
3365\end{array}$} & \multicolumn{2}{|c|}{$\begin{array}{c}354213 \\
350850 \\
3363\end{array}$} & \multicolumn{2}{|c|}{$\begin{array}{c}360090 \\
359411 \\
679\end{array}$} & \multicolumn{2}{|c|}{$\begin{array}{c}360105 \\
359411 \\
694\end{array}$} \\
\hline
\end{tabular}

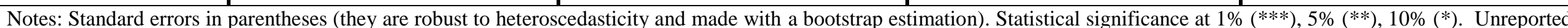

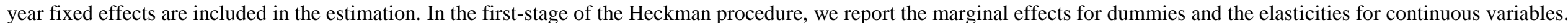

